\title{
The role of the AEWA in phasing out lead shot for hunting in wetlands*
}

\author{
BERT LENTEN
}

\section{Introduction}

Herewith the UNEP/AEWA Secretariat gives a response to the paper by Vernon G. Thomas and Raimon Guitart entitled "Role of international conventions in promoting avian conservation through lead toxicosis: progression towards a non-toxic agenda".

The response will firstly describe the activities undertaken so far under the auspices of the AEWA to phase out lead shot for hunting in wetlands; secondly it will describe future activities; and finally some concluding remarks will be made.

\section{Activities undertaken so far}

The starting point for all activities undertaken so far is the Agreement text and in particularly the Action Plan annexed to it. The position of the AEWA regarding lead shot is laid down in paragraph 4.1.4, which reads: "Parties shall endeavour to phase out the use of lead shot for hunting in wetlands by the year 2000".

The first Session of the Meeting of the Parties (MOP), which took place a few days after the Agreement actually entered into force in November 1999, reviewed what progress had been made regarding the implementation of paragraph 4.1.4. The MOP acknowledged that many Range States had technical difficulties in phasing out lead shot. By adoption of Resolution I.14 the MOP requested the Technical Committee to review the experience of those countries that have phased out, or are endeavouring to phase out, the use of lead shot for hunting in wetlands, in consultation with hunting organizations, gun and ammunition manufacturers and traders, and accordingly bring guidance to the MOP at its second session.

As follow-up on Resolution 1.14 the Technical Committee discussed the issue of phasing out lead shot several times. Furthermore the UNEP/AEWA Secretariat in close cooperation with the Federation of Associations for Hunting and Conservation of the EU organized, in October 2001, a workshop to raise awareness of the problems caused by lead shot and the availability of alternatives in Eastern Europe. At this workshop, representatives from the National Hunter Organization from Eastern Europe participated as policy officers from that region. One of the recommendations made at this workshop was to raise awareness of the problem and possible solutions among user groups and decision makers, through: materials for grass-root level in

\footnotetext{
${ }^{*}$ Representatives of the Conventions discussed in the paper by Thomas and Guitart in this issue were invited to comment on the paper. The following response was received from Bert Lenten, Executive Secretary of the AEWA. Ed.
} 
appropriate languages (leaflets/hand-outs, etc.); special issues of AEWA/FACE/CIC newsletters; hunting magazines, etc. The Agreement Secretariat implemented this recommendation by publishing a special Newsletter on non-toxic shot.

During the second session of the MOP (September 2002) progress made regarding implementation of the phasing out of lead shot for hunting in wetlands was reviewed. The MOP decided not to amend paragraph 4.1.4 of the Action Plan by inserting a new deadline for phasing out lead shot but instead to adopt Resolution 2.2. In accordance with this Resolution, Parties are called upon to enhance their efforts to phase out the use of lead shot in wetlands. Parties are also called upon to report to each ordinary session of the MOP on progress made to phase out lead shot in accordance with selfimposed and published timetables, and to specify how they plan to overcome any problems encountered. The Secretariat was requested to gather and to disseminate knowledge and expertise at the international level by making information material available and by organizing additional theoretical and practical workshops for hunters in different regions as appropriate. The Agreement Secretariat was also requested to assist countries, especially developing countries and those in economic transition, to achieve the phasing out of lead shot. One of the concrete actions undertaken by the Agreement Secretariat was to draft several articles on the lead shot issue. These articles were distributed to National Hunter Organizations all over Europe. They were requested to translate these articles into the local language and to publish them in their magazine. To make this information accessible for others these articles were put on the Agreement's website (see: http://www.unep-aewa.org/eng/info/Leadshot/ leadpageı.htm). In addition the Secretariat tried to organize a workshop on non-toxic shot for southern Europe. Unfortunately no counterpart for the National Hunter organizations could be identified that was willing to organize such a workshop in close cooperation with the Agreement Secretariat.

It is clear that for a number of activities the Agreement Secretariat has to rely on support from international federations of hunting associations, on manufacturers and regarding funding on Contracting Parties and/or, for example, the European Commission. These issues are also captured in the Resolution 2.2.

The second session of the MOP reiterated in Resolution 2.2 what was already laid down in Resolution 1.14: that the Technical Committee would review the experiences of those countries that have phased out, or are endeavouring to phase out, the use of lead shot for hunting in wetlands, in consultation with hunting organizations, gun and ammunition manufacturers and traders, and to map the situation in all the Range States, and accordingly bring elaborate guidance to the MOP at its third session.

\section{Future activities}

As mentioned above, much information has been drafted and disseminated widely over the last few years. In due course the special issue of the AEWA Newsletter on non-toxic shot will be translated into Russian and distributed to Russian-speaking countries.

In close cooperation with Office National de la Chasse et Faune Sauvage (France), OMPO, CIC and Wetlands International, an AEWA Workshop on Sustainable Hunting will be organized for Western Africa. This workshop is scheduled to take place in October 2004 in Senegal and will focus, among other things, on phasing out the use of lead shot for hunting in wetlands. 
Although already scheduled for some years, a workshop on non-toxic shot for southern Europe did not take place due to organizational problems. It is hoped that these problems can be overcome in due course so that such a workshop could take place in 2005/2006. Similar workshops for other regions will be considered for the future.

\section{Conclusion}

Without any question lead ammunition is a severe threat to species and habitats worldwide. This threat is taken very seriously by the AEWA and therefore the Agreement Secretariat will continue to raise awareness on the toxicity of spent lead and will promote the use of non-toxic shot. Although progress on phasing out lead shot has been made over the last few years, particularly in Western Europe, there is still a long way to go before the use of lead shot is banned in the whole Agreement Area. The "critical mass" of countries that have phased out lead shot has not yet been achieved. As soon as this point is reached the phasing out of lead shot in the remaining countries will probably go smoothly.

Today there are still hunters who believe that the use of non-toxic shot will damage their guns. Others think that lead shot is more effective than non-toxic shot. Another issue often raised is the higher cost of non-toxic shot cartridges compared with lead shot; sometimes even twice the price. There are many other issues raised by hunters that have made them reluctant to switch to alternatives. A lesson learned from countries where the use of lead shot is banned is that hunters quickly adjust themselves to use the non-toxic alternative, that the price of non-toxic shot is going down quickly and that afterwards all foreseen problems seem to be solved or forgotten.

To phase out the use of lead shot for hunting in wetlands, assistance is needed from the international hunter associations. So far the Agreement Secretariat has established a close working relationship with the Federation of Association for Hunting and Conservation of the EU (FACE) and with the International Hunting Council (CIC). At their last General Assembly the CIC adopted a Resolution on phasing out lead shot for hunting in wetlands, so some progress has been made. Nonetheless more awarenessraising campaigns are needed to convince hunters to use non-toxic shot instead of lead shot for hunting in wetlands.

One of the weak points is the role taken by the manufacturers of ammunitions to phase out the production of lead shot. Information received from them shows that they could easily switch from lead to non-toxic alternatives. However, as long there is no market for non-toxic shot they are reluctant to switch their production from lead shot to alternative non-toxic shot.

Thus the conclusion could be that having provisions in Multilateral Environmental Agreements such as the AEWA is a first step towards phasing out lead shot. To implement such a provision the cooperation of all stakeholders involved will be essential to ensure that the use of lead shot is phased out in the next 10 years. 